\title{
Leptospirosis in Indonesia: diagnostic challenges associated with atypical clinical manifestations and limited laboratory capacity
}

Muhammad Hussein Gasem¹, Usman Hadi ${ }^{2}$, Bachti Alisjahbana ${ }^{3}$, Emiliana Tjitra ${ }^{4}$, M. M. D. E. A. H. Hapsari ${ }^{1}$, Endang Sri Lestari ${ }^{1}$, Abu Tholib Aman ${ }^{5}$, Dewi Lokida ${ }^{6}$, Gustiani Salim ${ }^{7}$, Herman Kosasih ${ }^{7^{*}}$ (D), Ketut Tuti Parwati Merati ${ }^{8}$, Kanti Laras ${ }^{7}$, Mansyur Arif ${ }^{9}$, Nurhayati Lukman ${ }^{7}$, Pratiwi Sudarmono ${ }^{10}$, Vivi Lisdawati ${ }^{11}$, Chuen-Yen Lau ${ }^{12}$, Aaron Neal ${ }^{12}$ and Muhammad Karyana ${ }^{4,7}$

\begin{abstract}
Background: The burden of leptospirosis in Indonesia is poorly understood. Data from an observational study conducted from 2013 to 2016 in seven cities across Indonesia was used to estimate the incidence of leptospirosis and document its clinical manifestations in patients requiring hospitalization.

Methods: Specimens from patients hospitalized with acute fever were collected at enrollment, 14-28 days, and 3 months. Demographic and clinical information were collected during study visits and/or retrieved from medical records and double-entered into clinical report forms. After initially screening for dengue virus and other pathogens, specimens were tested at a central Reference Laboratory for anti-Leptospira IgM using commercial ELISA kits and for Leptospira DNA using an in-house quantitative real-time PCR assay.

Results: Of 1464 patients enrolled, 45 (3.1\%) confirmed cases (by PCR and/or sero-coversion or four-fold increase of $\lg \mathrm{M})$ and $6(0.4 \%)$ probable cases (by high titer $\operatorname{lgM}$ ) of leptospirosis were identified by the Reference Laboratory. Disease incidence at sites ranged from $0(0 \%)$ cases in Denpasar to 17 (8.9\%) cases in Semarang. The median age of patients was 41.2 years (range of 5.3 to 85.0 years), and $67 \%$ of patients were male. Twenty-two patients (43.1\%) were accurately diagnosed at sites, and 29 patients (56.9\%) were clinically misdiagnosed as having another infection, most commonly dengue fever (11,37.9\%). Clinically, 20 patients (39.2\%) did not present with hyperbilirubinemia or increased creatinine levels. Two patients (3.9\%) died, both from respiratory failure. Fifteen patients (29.4\%) clinically diagnosed with leptospirosis at sites were negative based on IgM ELISA and/or PCR at the Reference Laboratory.

Conclusions: Leptospirosis remains an important cause of hospitalization in Indonesia. It can have diverse clinical presentations, making it difficult to differentiate from other common tropical infections. PCR combined with ELISA is a powerful alternative to the cumbersome gold-standard microscopic agglutination test, particularly in resourcelimited settings.
\end{abstract}

Keywords: Leptospirosis, Diagnostic challenge, Atypical manifestations, Indonesia

\footnotetext{
* Correspondence: hkosasih@ina-respond.net

${ }^{7}$ Indonesia Research Partnership on Infectious Disease (INA-RESPOND), Badan

Litbangkes, Building 4, 5th floor, Jl Percetakan Negara no 29, Jakarta 10560,

Indonesia

Full list of author information is available at the end of the article
}

(c) The Author(s). 2020 Open Access This article is distributed under the terms of the Creative Commons Attribution 4.0 International License (http://creativecommons.org/licenses/by/4.0/), which permits unrestricted use, distribution, and reproduction in any medium, provided you give appropriate credit to the original author(s) and the source, provide a link to the Creative Commons license, and indicate if changes were made. The Creative Commons Public Domain Dedication waiver (http://creativecommons.org/publicdomain/zero/1.0/) applies to the data made available in this article, unless otherwise stated. 


\section{Background}

Leptospirosis is a significant, but often overlooked, bacterial infection endemic in tropical and sub-tropical regions. Though its detected burden is low relative to other tropical diseases in Indonesia, most notably dengue fever, leptospirosis remains a significant public health problem, especially in regions that experience heavy rain and flooding [1]. This potentially life-threatening but treatable zoonosis caused an estimated 895 human cases in Indonesia during 2018, with a case fatality rate of $17.8 \%$, according to official Ministry of Health $(\mathrm{MoH})$ reports [2] However, this case number is certainly a severe underestimate of leptospirosis in Indonesia given that the annual morbidity of leptospirosis in the population was recently estimated at 39.2 per 100 , 000 [3]. The significant discrepancy between observed cases and case estimates highlights the poor understanding of the leptospirosis burden in Indonesia and the clear need for additional epidemiological data.

Physicians in Indonesia are generally unfamiliar with the clinical presentations of leptospirosis, which include non-specific anicteric and flu-like manifestations in the majority of cases. Associated manifestations such as acute fever, headache, chills, and myalgia overlap with those of dengue and typhoid fevers [4], which are more common than leptospirosis in Indonesia. Timely diagnosis of this treatable bacterial infection is critical for appropriate case management. Untreated cases are at an increased risk of progression to the severe manifestation of Weil's disease, which has a $>70 \%$ case fatality rate [3].

In addition to diverse clinical symptoms and overlapping presentation with other endemic infections, poor access to accurate diagnostic tests complicates the diagnosis of leptospirosis $[5,6]$. The serological 'gold-standard' microscopic agglutination test (MAT), which requires considerable resources and trained staff $[5,6]$, is only available at three centers in all of Indonesia. Alternative tests such as qPCR, which can detect infection early in the course of the disease, are seldom available in resource-limited settings where leptospirosis is common. The resulting under-diagnosis of leptospirosis perpetuates low awareness and poor understanding of disease epidemiology [6].

To characterize the clinical manifestations, diagnostic challenges, and outcomes of endemic leptospirosis requiring hospitalization in Indonesia, we analyzed demographic, clinical, and laboratory data from patients enrolled in a multi-site observational study conducted at eight tertiary care hospitals across the country from 2013 to 2016.

\section{Methods}

\section{Study population}

Patients were enrolled in the Etiology of Acute Febrile Illness Requiring Hospitalization (AFIRE) cohort study, conducted by the INA-RESPOND (Indonesia Research Partnership on Infectious Diseases) research network [7] in Indonesia from 2013 to 2016. The AFIRE study recruited patients at eight tertiary-care hospitals who presented for evaluation of acute fever, were at least 1 yearold, were hospitalized within the past $24 \mathrm{~h}$, and had not been hospitalized within the past 3 months. Clinical information and biological specimens were collected at enrollment, 14-28 days after enrollment, and 3 months after enrollment. Details of the AFIRE study have been previously described [8].

\section{Reference laboratory evaluation for leptospirosis}

Serological assays for anti-Leptospira IgM were performed on both acute and convalescent samples in parallel. As the sensitivities of IgM-specific ELISAs range from 43 to 90.8\% [9, 10], ELISA IgM kits from two manufacturers were used. The SERION ELISA classic Kit (Cat\# ESR125G, Institut Virion/Serion GMBH-Germany) was performed according to the manufacturer's instructions. Antibody activity was automatically calculated using SERION software. For IgM, $<15 \mathrm{U} / \mathrm{mL}$ was interpreted as negative, $15-20 \mathrm{U} / \mathrm{mL}$ as borderline, and $>20 \mathrm{U} / \mathrm{mL}$ as positive. Additionally, the PanBio Leptospira IgM ELISA (PanBio Cat\# 02PE10, Standard Diagnostics Inc., Gyeonggi-do, Korea) was performed following the manufacturer's instructions. An index value was calculated by dividing the sample absorbance by the cut-off value. An index value of $<0.9$ was interpreted as negative, index $>$ 0.9 to $<1.1$ as borderline, and index $>1.1$ as positive.

Acute specimens of patients sero-positive for Leptospira were further tested using an in-house TaqMan realtime PCR assay to confirm the presence of pathogenic Leptospira DNA. Briefly, DNA was extracted from $200 \mu \mathrm{l}$ of buffy coat or plasma from acute specimens using the QIAamp DNA Blood Mini Kit (Qiagen, de Hilden Germany). Extracts were then used to perform a TaqMan real time PCR assay targeting the rrs and lipL32 genes of Leptospira spp. Amplifications were done using TaqMan Fast Universal PCR Master Mix (Thermo Fisher Scientific) and run on an Applied Biosystem 7500 Fast real-time PCR instrument. Primers, probes, and procedures are described in detail in the references (11, 12). When results differed between the rrs and lipL32 qPCR assays, positive results from each qPCR assay were considered valid when supported by serological evidence. The reference standard MAT was not performed due to study limitations. Although one hospital in Indonesia has the capability of conducting MAT, it was not utilized in the AFIRE study.

\section{Case definition of leptospirosis}

Taking into consideration the diverse clinical manifestations of leptospirosis, the limited availability of diagnostics, and the need for early case detection and treatment, the U.S. Centers for Disease Control and Prevention 
developed a leptospirosis case definition [13]. For this study, the case definition was adapted as follows:

Probable Leptospirosis is a clinically suspected leptospirosis case with a high titer $(\geq 1600)$ of ELISA IgM antibodies by both Serion and PanBio assays; Confirmed Leptospirosis is a clinically suspected leptospirosis case with a positive qPCR result from plasma or buffy coat and/or a four-fold increase or sero-conversion in the convalescent specimen of ELISA IgM antibodies by Serion and/or PanBio assays.

\section{Statistical analysis}

Data were collected in OpenClinica v.3.1 (OpenClinica, LLC) and analyzed using STATA v.15.1 (StataCorp LLC). Proportions were compared between groups using the chi-square test. The t-test was used to compare means between groups.

\section{Results}

\section{Epidemiology}

The AFIRE study enrolled 1486 patients. Of 1464 with available specimens, 37 were clinically suspected of having leptospirosis. Of the 1427 not suspected of having leptospirosis, 966 had no pathogen identified. Samples from patients suspected of having leptospirosis and from patients with no pathogen identified were tested for leptospirosis as described above. Evidence of Leptospira infection was found in 22 of the 37 clinically suspected patients and 29 of the 966 without an identified pathogen (Fig. 1).

The 51 leptospirosis cases constitute $5.1 \%$ of tested patients and $3.5 \%$ of enrolled patients. Most cases were from Semarang $(17 / 51,33.3 \%)$ and Surabaya (12/51, $23.5 \%)$, which is not a statistically significant distribution compared to the other sites $(1.9, p=0.17)$. Additionally, the proportion of leptospirosis amongst tested patients was significantly higher in Semarang $(17 / 191,8.9 \%)$ and Surabaya $(12 / 168,7.1 \%)$ compared to other sites (14.191, $p=0.028)$. There were no cases from Denpasar. Leptospirosis tended to be more common in men $(34 / 51,67 \%)(3.722, p=0.054)$ and in adults $>45$ years (9.6\%) compared to adults $>18-45$ years $(5.9 \%)(2.939$, $p=0.086)$ and pediatrics $1-\leq 18$ years (1.3\%) (23.208, $p<0.001)$. The distribution of cases in each city grouped by gender and age categories is shown in Fig. 2.

\section{Laboratory diagnostic tests}

Thirty-three of the 51 leptospirosis cases were confirmed by PCR. Leptospira DNA was detected in blood and urine for one patient, blood-only for 29 patients, and urine-only for three patients. In these three cases, Leptospira ELISA IgM results were supportive. Twelve cases were confirmed by Leptospira ELISA IgM seroconversion or four-fold increase. Six probable cases showed high IgM titer $(1 / 1600)$ in the acute specimen

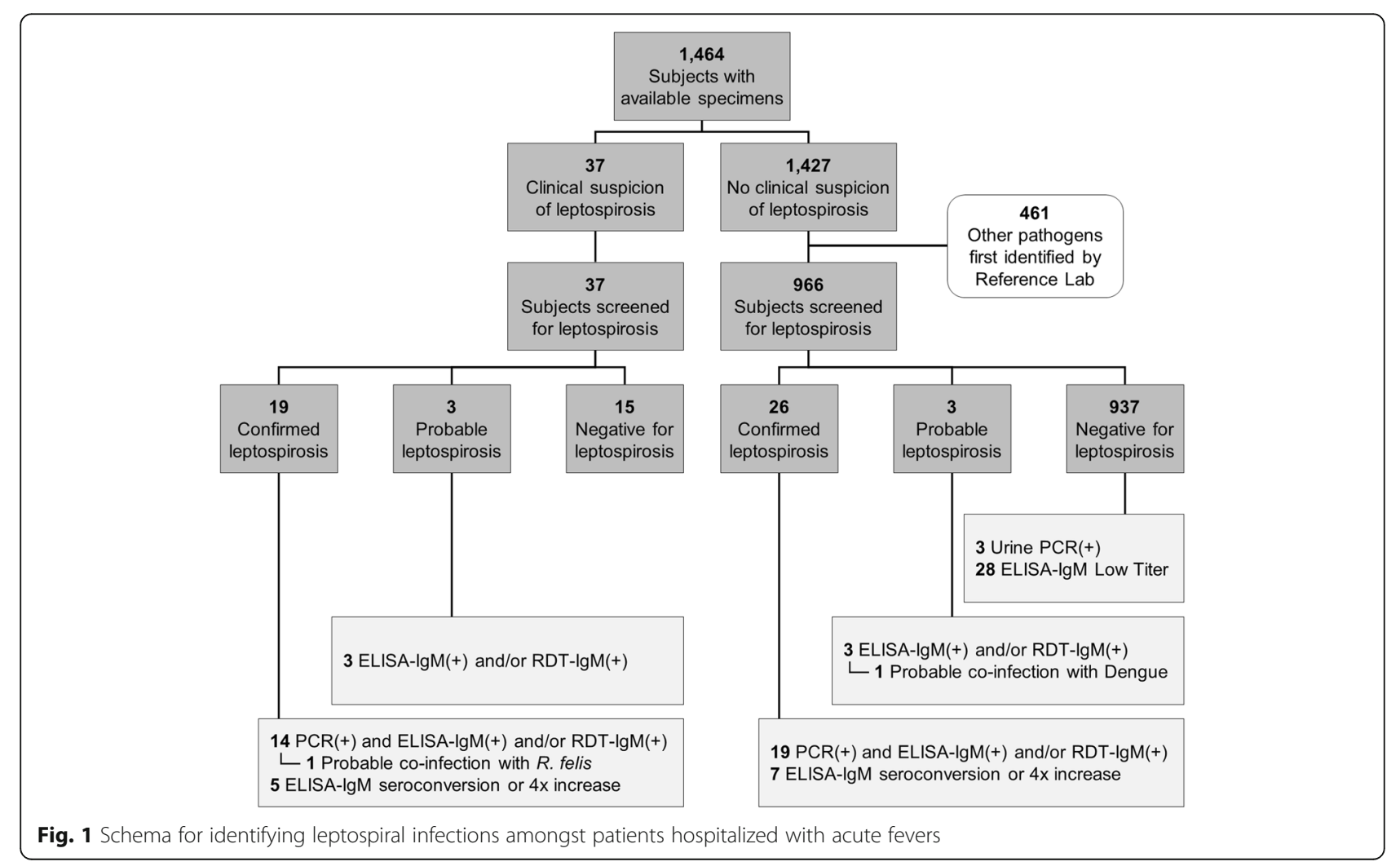




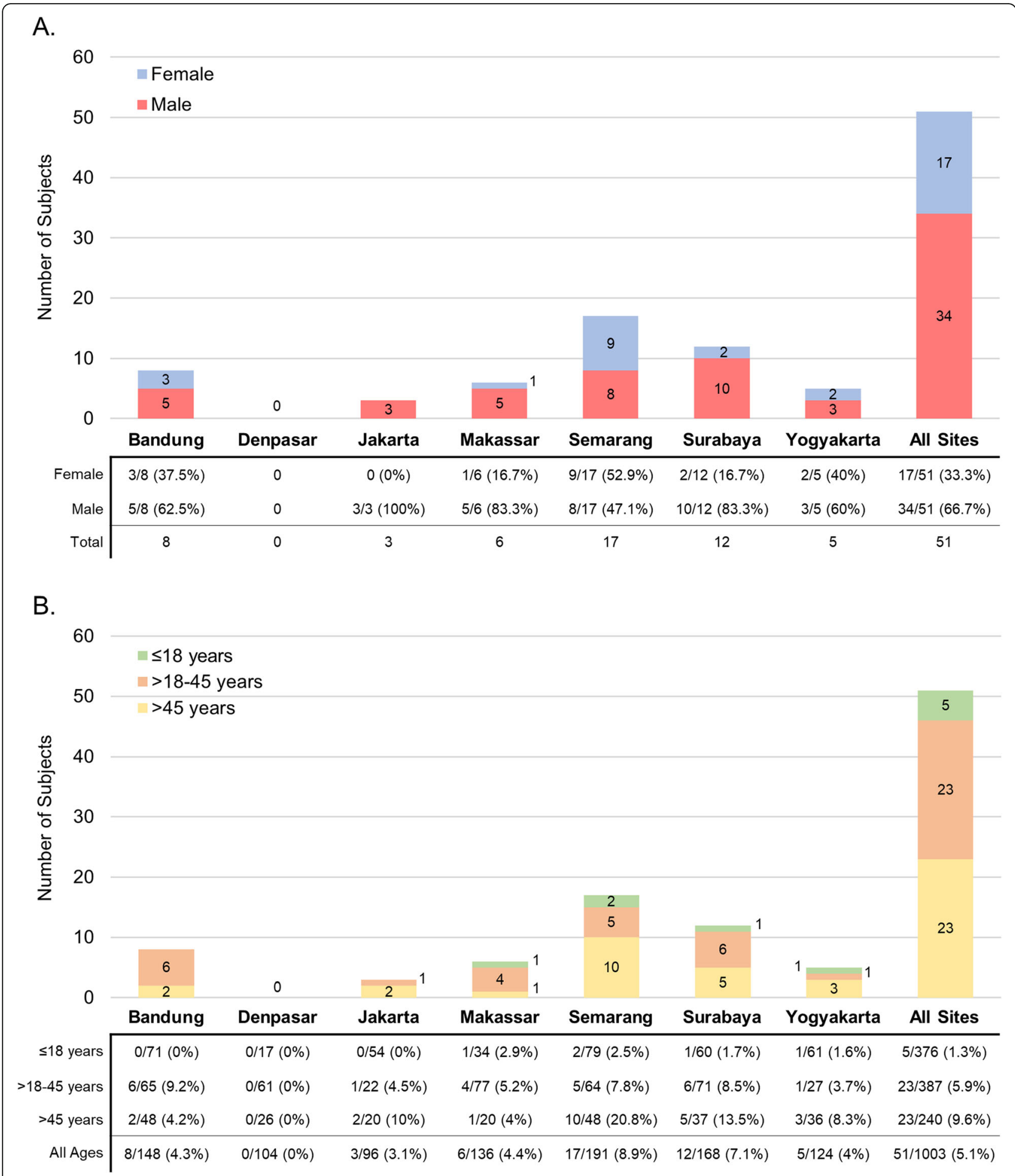

Fig. 2 Distribution of leptospirosis cases in each city by gender and age categories

by ELISA. The onset of illness in PCR-positive patients was significantly shorter than those who were PCRnegative (mean (SD): 4.58 (1.66) days vs. 5.78 (2.44) days) $(\mathrm{t}(49)=(-2.088) ; p=0.042)$. One patient with detected Leptospira DNA and sero-conversion of both
Leptospira IgM antibodies was also positive for Rickettsia felis, suggesting dual infection.

Three patients diagnosed with urinary tract infections (UTI) had detectable Leptospira DNA in the urine. As diagnosis of leptospirosis was not supported by 
Leptospira IgM or Leptospira DNA in the blood, the 3 patients were not included as acute cases. The 28 patients with non-increasing detectable ELISA IgM antibodies in lower titers (1:100-1:400) were also not included as cases.

\section{Clinical presentations}

At the hospital sites, leptospirosis was not diagnosed in $29(56.9 \%)$ of the 51 cases detected by the Reference Laboratory (missed cases). Yogyakarta, Makassar, and Surabaya had the highest missed case rates $(100,83.3$, and $83.3 \%$, respectively). These cases were initially diagnosed as dengue fever $(11 / 29,37.9 \%)$, typhoid fever (4/ $29,13.8 \%)$, UTI $(5 / 29,17.2 \%)$, community-acquired pneumonia $(3 / 29,10.3 \%)$, diarrhea $(2 / 29,6.9 \%)$, sepsis, undifferentiated fever, pharyngitis, and ulcer $(1 / 29,3.4 \%$, each). The characteristics of Reference Laboratoryconfirmed leptospirosis cases according to initial clinical diagnoses at sites are shown in Table 1.

Leptospirosis could not be confirmed in 15 of 37 (40.5\%) subjects clinically diagnosed at the sites, mostly from Semarang 12/15 (80\%). Reference Laboratory testing revealed evidence of Rickettsia typhi in four cases and Staphylococcus aureus, chikungunya virus, and dengue virus in one case each. Etiologies remained unknown in eight cases. All 15 patients were adults, with a median age of 36.8 years (range 20.2-62.8), and were predominantly male (10:5). Hematological findings consistent with leptospirosis, such as leukocytosis, thrombocytopenia, and granulocytosis, were found in $46.7 \%$ (7/15), 53.3\% $(8 / 15)$, and $42.9 \%(6 / 14)$ of the cases, respectively. Hyperbilirubinemia and increased creatinine levels were reported in $33.3 \%(5 / 15)$ and $20 \%(3 / 15)$ of the cases, respectively. In 11 of the cases, leptospirosis could not be confirmed by further testing despite observing low ELISA IgM antibody titers for one case and positive rapid IgM tests for ten cases. In 3 cases, rapid IgM was negative, and in one case, rapid IgM was not done. In these 4 cases, the diagnosis of leptospirosis was based solely on clinical judgement. Single MAT was done in 5 of 15 patients as part of study-independent standard-ofcare testing, and none were positive. The INARESPOND Reference Laboratory found ELISA IgM antibody and qPCR assays to be negative in 12 patients. Low IgM titers were detected in three patients, but none were further supported by increasing IgM titers or Leptospira nucleic acid detection. Details of the clinical presentations and diagnostic assays from each patient are shown in Table 2.

The median onset of fever was 5 days (range 2-11) prior to presentation. In the 49 of 51 Reference Laboratory-diagnosed patients who survived, the median hospitalization time was 6 days (range 3-18). All 51 cases received antibiotics, including ceftriaxone (26 cases), ciprofloxacin (10 cases), doxycycline (5 cases), ampicillin, azithromycin, levofloxacin, cefotaxime, and cefixime (1 case each), a combination of antibiotics (4 cases), and unknown antibiotics (1 case). Leptospirosis patients correctly diagnosed at sites were hospitalized longer than those misdiagnosed (mean (SD): 8.91 (3.78) days vs. 5.28 (1.73) days, $\mathrm{t}(49)=4.593 ; \mathrm{p}=<0.0001$ ).

The two leptospirosis patients (4\%) who died during hospitalization were misdiagnosed cases. The first was a male clinically diagnosed with dengue hemorrhagic fever, and the second was a diabetic female clinically diagnosed with typhoid fever. Both came to the hospital 3 days after fever onset and died 2 days later. Details of their clinical and laboratory findings are shown in Table 3.

\section{Discussion}

Acute infection with Leptospira was identified in 3.5\% of our cohort of patients hospitalized with acute febrile illness in Indonesia. This number could be an underreporting of the total number of cases in the cohort given that febrile cases confirmed as dengue virus infections were not examined for co-infection with Leptospira due to study resource limitations. We know of no other recent studies reporting the incidence of leptospirosis from seven large cities across Indonesia. Previously published reports have been from Jakarta in 1993-1995 [14], Papua in 1997-2000 [14], Semarang in 1995-1996 and 2005-2009 [15-17], Tangerang in 2015 [18], and returning travelers from Sumatra and Bali in 2008 and 2013 $[19,20]$. Rates of acute leptospirosis in our study ranged from $0 \%$ in Denpasar to $8.9 \%$ in Semarang, likely reflecting country-wide variations in endemicity. However, prior reports of leptospirosis in travelers returning from Bali suggest that our study results may not be representative or that the epidemiology of leptospirosis is changing. Our findings are consistent with $\mathrm{MoH}$ data in which only 8 of 34 provinces in Indonesia (6 on Java island) reported 895 leptospirosis cases in 2018, with the highest incidence being in Central (613 cases) and East (128 cases) Java provinces [2] where our 3 sites in Semarang (17/51 cases), Yogyakarta (5/51 cases), and Surabaya (12/51 cases) are located. As we found leptospirosis in Makassar, where there are no documented cases according to the MoH report [2], we recommend continued surveillance for leptospirosis, particularly in provinces where its epidemiology has not been characterized. This will facilitate the development of targeted risk reduction strategies. Missed cases in our study were predominantly mild and without pathognomonic signs or symptoms of leptospirosis. There was a surprisingly high number of patients with GI symptoms such as nausea $(40 / 51,78.4 \%)$ and vomiting $(32 / 51,62.7 \%)$, including in both fatal cases. These symptoms were also 
Table 1 Characteristics of confirmed leptospirosis cases according to initial clinical diagnoses at sites

\begin{tabular}{|c|c|c|c|c|c|c|c|}
\hline & \multicolumn{7}{|c|}{ Clinical Diagnosis at Site } \\
\hline & $\begin{array}{l}\text { Dengue } \\
(n=11)\end{array}$ & $\begin{array}{l}\text { Typhoid fever } \\
(n=4)\end{array}$ & $\begin{array}{l}\text { UTI } \\
(n=5)\end{array}$ & $\begin{array}{l}\text { CAP } \\
(n=3)\end{array}$ & $\begin{array}{l}\text { Other }^{a} \\
(n=6)\end{array}$ & $\begin{array}{l}\text { Leptospirosis } \\
(n=22)\end{array}$ & $\begin{array}{l}\text { Total } \\
(n=51)\end{array}$ \\
\hline \multicolumn{8}{|l|}{ Demography } \\
\hline Gender (male: female) & 10:1 & $1: 3$ & $2: 3$ & $2: 1$ & $3: 3$ & $16: 6$ & $34: 17$ \\
\hline Adult: Pediatric $^{b}$ & $9: 2$ & $4: 0$ & $4: 1$ & $3: 0$ & $4: 2$ & $22: 0$ & $46: 5$ \\
\hline Age, median (range) & $29(5.3-58.1)$ & $42.3(19.2-60.4)$ & $27(10-61.4)$ & $62.5(59.7-64.4)$ & $47(13-85)$ & $41.7(20.8-62.1)$ & $41.2(5.3-85)$ \\
\hline \multicolumn{8}{|l|}{ Signs \& Symptoms, N (\%) } \\
\hline Anorexia & $3(27.3)$ & $2(50)$ & 0 & $1(33.3)$ & $3(50)$ & $7(31.8)$ & $16(31.4)$ \\
\hline Chills & $4(36.4)$ & $2(50)$ & $3(60)$ & $2(66.7)$ & $1(16.7)$ & $9(40.9)$ & $21(41.2)$ \\
\hline Lethargy & $2(18.2)$ & $1(25)$ & $1(20)$ & 0 & $1(16.7)$ & $10(45.5)$ & $15(29.4)$ \\
\hline Icterus & $2(18.2)$ & 0 & 0 & 0 & $1(16.7)$ & $6(27.3)$ & $9(17.6)$ \\
\hline Decrease of consciousness & 0 & 0 & 0 & 0 & $1(16.7)$ & 0 & $1(1.9)$ \\
\hline Headache & $5(45.5)$ & $3(75)$ & $3(60)$ & $1(33.3)$ & $3(50)$ & $13(59.1)$ & $28(54.9)$ \\
\hline Dizziness & $2(18.2)$ & $1(25)$ & $3(60)$ & $2(66.7)$ & $2(33.3)$ & $6(27.3)$ & $16(31.4)$ \\
\hline Cough & $2(18.2)$ & 0 & $1(20)$ & $1(33.3)$ & $2(33.3)$ & $9(40.9)$ & $15(29.4)$ \\
\hline Shortness of breath & 0 & 0 & 0 & 0 & 0 & $4(18.2)$ & $4(7.8)$ \\
\hline Epigastric pain & 0 & $2(50)$ & $2(40)$ & $1(33.3)$ & $1(16.7)$ & $8(36.4)$ & $14(27.5)$ \\
\hline Abdominal pain & $2(18.2)$ & 0 & 0 & 0 & $1(16.7)$ & $5(22.7)$ & $8(15.7)$ \\
\hline Nausea & $8(72.7)$ & $4(100)$ & $4(80)$ & 3 & $4(66.7)$ & $17(77.3)$ & $40(78.4)$ \\
\hline Vomiting & $7(63.6)$ & $3(75)$ & $3(60)$ & $2(66.7)$ & $5(83.3)$ & $12(54.5)$ & $32(62.7)$ \\
\hline Constipation & $2(18.2)$ & $2(50)$ & 0 & 0 & $1(16.7)$ & 0 & $5(9.8)$ \\
\hline Diarrhea & $5(45.5)$ & 0 & $2(40)$ & $2(66.7)$ & $3(50)$ & $9(40.9)$ & $21(41.2)$ \\
\hline Arthralgia & $2(18.2)$ & 0 & $4(80)$ & $2(66.7)$ & 0 & $12(54.5)$ & $20(39.2)$ \\
\hline Myalgia & $1(9.1)$ & $1(25)$ & $3(60)$ & $1(33.3)$ & $1(16.7)$ & $15(68.2)$ & $22(43.1)$ \\
\hline Skin rash & 0 & 0 & 0 & $1(33.3)$ & 0 & $1(4.5)$ & $2(3.9)$ \\
\hline Conjunctival suffusion & $2(18.2)$ & 0 & 0 & 0 & $1(16.7)$ & $11(50)$ & $14(27.5)$ \\
\hline Rhonchi & 0 & 0 & 0 & $2(66.7)$ & 0 & $4(18.2)$ & $6(11.8)$ \\
\hline Pruritus & 0 & $1(25)$ & 0 & 0 & 0 & 0 & $1(1.9)$ \\
\hline Gastrocnemius pain & $1(9.1)$ & 0 & 0 & 0 & $1(16.7)$ & $6(27.3)$ & $8(15.7)$ \\
\hline Oliguria & $1(9.1)$ & 0 & 0 & 0 & 0 & $3(13.6)$ & $4(7.8)$ \\
\hline Brown-coloured urine & 0 & 0 & 0 & 0 & 0 & $7(31.8)$ & $7(13.7)$ \\
\hline \multicolumn{8}{|c|}{ Haematology \& Chemistry Results, N (\%) / N/tested (\%) } \\
\hline Leukopenia & 0 & 0 & $1(20)$ & 0 & $1(16.7)$ & 0 & $2(3.9)$ \\
\hline Normal leucocyte count & $10(90.9)$ & $3(75)$ & $2(40)$ & $2(66.7)$ & 0 & $6(27.3)$ & $23(45.1)$ \\
\hline Leukocytosis & $1(9.1)$ & $1(25)$ & $2(40)$ & $1(33.3)$ & $5(83.3)$ & $16(72.7)$ & $26(50.9)$ \\
\hline Platelet $\leq 150,000 / \mathrm{mm}^{3}$ & $8(72.7)$ & $2(50)$ & $1(20)$ & $2(66.7)$ & $1(16.7)$ & $16(72.7)$ & $30(58.8)$ \\
\hline Granulocytosis > 80\% & $8 / 10(80)$ & $2 / 3(66.7)$ & $1 / 4(25)$ & $2 / 2(100)$ & $3 / 5(60)$ & 10/12 (83.3) & $26 / 36(72.2)$ \\
\hline Lymphopenia < 20\% & 9/10 (90) & 4/4 (100) & $2 / 4(50)$ & $2 / 2(100)$ & $5 / 5(100)$ & $13 / 13(100)$ & $35 / 38(92.1)$ \\
\hline Total bilirubin > $1 \mathrm{mg} / \mathrm{dL}$ & $3 / 11(27.3)$ & $1 / 3(33.3)$ & $0 / 4$ & $1 / 3(33.3)$ & $0 / 5$ & $15 / 22(68.2)$ & $20 / 48(41.7)$ \\
\hline Bilirubin direct $>0.65 \mathrm{mg} / \mathrm{dL}$ & 2/11 (18.2) & $1 / 3(33.3)$ & $0 / 4$ & $0 / 3$ & $0 / 5$ & $16 / 22(72.7)$ & 19/48 (39.6) \\
\hline $\mathrm{AST}^{\mathrm{C}}>100$ & $1 / 11(9.1)$ & $0 / 3$ & $0 / 4$ & $0 / 3$ & $0 / 6$ & $7 / 20(35)$ & $8 / 47(17)$ \\
\hline $\mathrm{ALT}^{\mathrm{d}}>100$ & $0 / 11$ & $0 / 3$ & $0 / 4$ & $0 / 3$ & $0 / 6$ & $3 / 22(13.6)$ & $3 / 47(6.4)$ \\
\hline Creatinine $>1.4 \mathrm{mg} / \mathrm{dL}$ & 3/11 (27.3) & $0 / 3$ & 2/4 (50) & $2 / 3(66.7)$ & $0 / 5$ & $15 / 22(68.2)$ & $22 / 48(45.8)$ \\
\hline
\end{tabular}

Diagnostic tests at sites, $\mathrm{N} /$ tested (\%) 
Table 1 Characteristics of confirmed leptospirosis cases according to initial clinical diagnoses at sites (Continued)

\begin{tabular}{|c|c|c|c|c|c|c|c|}
\hline & \multicolumn{7}{|c|}{ Clinical Diagnosis at Site } \\
\hline & $\begin{array}{l}\text { Dengue } \\
(n=11)\end{array}$ & $\begin{array}{l}\text { Typhoid fever } \\
(n=4)\end{array}$ & $\begin{array}{l}\text { UTI } \\
(n=5)\end{array}$ & $\begin{array}{l}\text { CAP } \\
(n=3)\end{array}$ & $\begin{array}{l}\text { Other }^{a} \\
(n=6)\end{array}$ & $\begin{array}{l}\text { Leptospirosis } \\
(n=22)\end{array}$ & $\begin{array}{l}\text { Total } \\
(n=51)\end{array}$ \\
\hline Dengue IgM positive & $2 / 6(33.3)$ & 2/4 (50) & $0 / 1$ & $0 / 1$ & $0 / 1$ & $0 / 5$ & $4 / 18(22.2)$ \\
\hline Tubex TF®e & $2 / 5(40)$ & $4 / 4(100)$ & $1 / 2(50)$ & $0 / 1$ & $1 / 3(33.3)$ & $2 / 5(40)$ & $10 / 20(50)$ \\
\hline Leptospira IgM positive & $0 / 1$ & $0 / 4$ & $0 / 1$ & $0 / 1$ & $0 / 1$ & 18/22 (81.8) & $18 / 25(72)$ \\
\hline \multicolumn{8}{|l|}{ Reference Laboratory tests, N (\%) } \\
\hline Dengue \& S. typhi & $1(9.1)$ & 0 & 0 & 0 & 0 & 0 & $1(1.9)$ \\
\hline Leptospira PCR \& Serology & $6(54.5)$ & $2(50)$ & $2(40)$ & $3(100)$ & $3(50)$ & $12(54.5)$ & $28(54.9)$ \\
\hline Leptospira PCR only & $2(18.2)$ & 0 & 0 & 0 & $1(16.7)$ & $2(9.1)$ & $5(9.8)$ \\
\hline Leptospira serology only & $3(27.3)$ & $2(50)$ & $3(60)$ & 0 & $2(33.3)$ & $8(36.4)$ & $18(35.3)$ \\
\hline \multicolumn{8}{|l|}{ Outcome, N (\%) } \\
\hline Death & $1(9.1)$ & $1(25)$ & 0 & 0 & 0 & 0 & $2(4)$ \\
\hline
\end{tabular}

a diarrhea (2), sepsis (1), pharyngitis (1), ulcus pedis (1), undifferentiated fever (1)

badult aged $\geq 18$ year old; pediatric aged $\geq 1-<18$ year old

Signs and symptoms in italics were not obtained from all patients as they were not included in the case report form. They were extracted from chart review

'AST: aspartate aminotransferase

${ }^{\mathrm{d}} \mathrm{ALT}$ : alanine aminotransferase

${ }^{\text {eTUBEX TF}}{ }^{\oplus}$ is a rapid diagnostic test to detect IgM antibodies against Salmonella typhi. Scores of 4-6 were considered positive

frequently found in our dengue, typhoid fever and rickettsioses cases (unpublished data). Observing these unexpected GI symptoms with leptospirosis should raise the index of suspicion among clinicians seeing acute febrile patients. As reports on the frequency of GI symptoms in leptospirosis vary [4, 21-23], further study is needed to better characterize the clinical manifestations of leptospirosis in endemic areas.

Missed cases tended to have shorter hospitalizations than accurately diagnosed cases. The frequency of missed cases we observed highlights the difficulty in diagnosing mild leptospirosis by its non-specific and variable clinical presentation. However, retrospective analyses revealed the presence of several typical markers, such as mild increases in bilirubin, transaminases, creatinine, and granulocytes, at enrollment in some patients. Thus, thorough laboratory and clinical evaluations remain key components of the diagnostic approach, particularly when other infections have been ruled out. Doxycycline is the recommended treatment for leptospirosis, and empiric administration against suspect or probable leptospirosis cases may prevent progression of the disease. Fortunately, doxycycline is indicated for both leptospirosis and rickettsiosis, so the drug would cover both frequently co-circulating diseases if a specific diagnosis was uncertain [24]. Intravenous penicillin should be initiated for clinically severe forms of the disease, which may contribute to decreasing mortality. In most cases, ceftriaxone may be used as an alternative $[25,26]$.

Similar diagnostic challenges have been reported in other nearby countries, including Thailand, where most missed cases were initially diagnosed as dengue fever, other viral infections, or scrub typhus [27]. In Semarang, where leptospirosis has been more frequently reported
$[15,16]$, the disease was over-diagnosed. Over-diagnosis is common when leptospirosis is prevalent [28], particularly when patients present with typical features of leptospirosis such as conjunctival suffusion or icterus. In 4 of 15 clinically-presumed cases, rickettsioses were confirmed, suggesting that these features are not exclusive to leptospirosis. Other diseases that may present with jaundice or acute kidney injury include cholecystitis, hepatitis, arbovirus infection, malaria, hantavirus infection, and rickettsioses $[29,30]$. As such, laboratory testing is needed to help distinguish the etiology.

Though a causal pathogen could not be confirmed in eight cases, it is unlikely that we missed leptospirosis given the extensive testing conducted. qPCR using primers for rrs and lipL32 genes was performed on both buffy coat and plasma [11, 12, 31], and two ELISAs for IgM, both with excellent sensitivity and specificity compared to MAT [10, 32], were performed using acute and convalescent specimens. However, the lack of diagnostic specificity with some tests, especially rapid tests [10], may contribute to the over-diagnosis of leptospirosis. Furthermore, IgM antibodies from past infections are frequently detected in people living in endemic areas, which complicates assay interpretation, particularly when a single specimen is used [33]. Our classification of 3 patients with positive urine PCR but low/undetectable IgM antibody titers as not having acute leptospirosis is consistent with prior findings that Leptospira bacteria may persist in urine for several months after recovery [34].

Our findings are consistent with previous reports that leptospirosis is less frequent in women and children. The findings are also consistent with reports of missed childhood cases, as all childhood cases in our cohort 


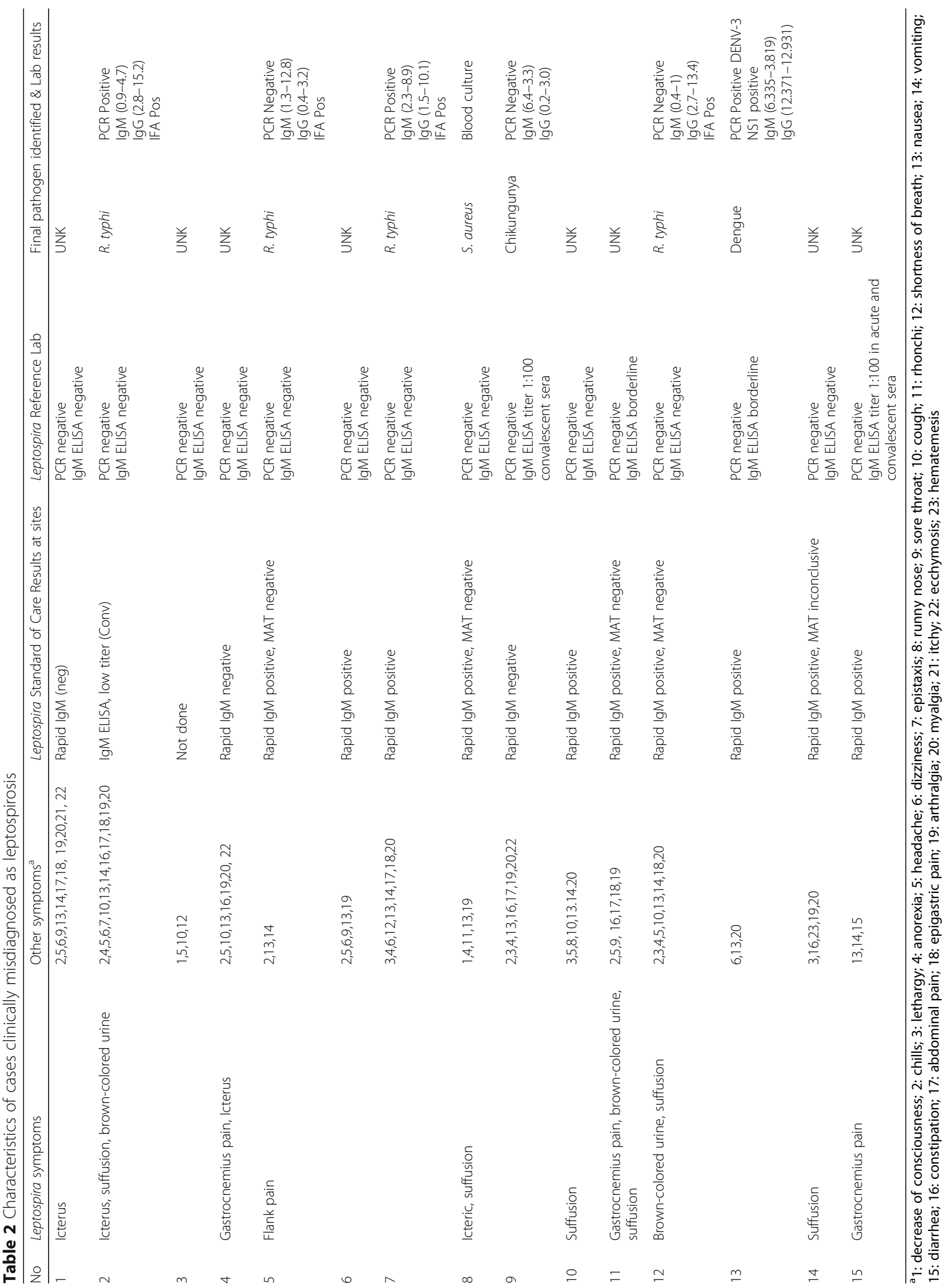


Table 3 Characteristics of the two fatal leptospirosis cases that were misdiagnosed

\begin{tabular}{|c|c|c|}
\hline & Patient 1 (Surabaya) & Patient 2 (Makassar) \\
\hline Gender, age range (years) & Male, 45-50 & Female, 60-65 \\
\hline Comorbidities & No comorbidities & Diabetes mellitus \\
\hline Signs/Symptoms & Fever ( 3 days), nausea, vomiting, diarrhea & Fever (3 days), chills, headache, dizzy, nausea, vomiting \\
\hline \multicolumn{3}{|l|}{ Hematology profiles } \\
\hline $\mathrm{Hb}(\mathrm{mg} / \mathrm{dL})$ & 11.5 & 13 \\
\hline Hematocrit (\%) & 32.9 & 38.7 \\
\hline Leukocyte count $\left(/ \mathrm{mm}^{3}\right)$ & 9600 & 9500 \\
\hline Granulocytes (\%) & $92 \%$ & Not available \\
\hline Lymphocytes (\%) & $3.8 \%$ & $6.9 \%$ \\
\hline Platelet $\left(/ \mathrm{mm}^{3}\right)$ & 45,000 & 118,000 \\
\hline \multicolumn{3}{|l|}{ Chemistries } \\
\hline Bilirubin total, direct, indirect (mg/dL) & $0.9 ; 0.6 ; 0.3$ & \\
\hline $\mathrm{AST}^{\mathrm{a}}(\mathrm{IU} / \mathrm{mL})$ & 139 & 93 \\
\hline $\mathrm{ALT}^{\mathrm{b}}(\mathrm{IU} / \mathrm{mL})$ & 33 & 64 \\
\hline Creatinine (mg/dL) & 4.1 & 1.1 \\
\hline \multicolumn{3}{|l|}{ Diagnostic tests at the hospital } \\
\hline Dengue test & Not tested & Negative IgM/lgG \\
\hline Salmonella typhi & Not tested & Tubex $\mathrm{TF}^{\oplus}$ test positive $[6]$ \\
\hline Diagnosis at the hospital & Dengue hemorrhagic fever grade I & Typhoid fever \\
\hline Antibiotics & Ceftriaxone & Cefotaxime, intra-venous \\
\hline Cause of death, hospitalization day & Respiratory failure, 2 days & Respiratory failure, 2 days \\
\hline \multicolumn{3}{|c|}{ Diagnostic test at the reference laboratory (only acute specimen available) } \\
\hline Dengue virus & RT-PCR, NS1, IgM negative, IgG positive & RT-PCR, NS1, IgM negative, IgG positive \\
\hline Salmonella typhi & Blood culture, PCR, ELISA IgM, IgG negative & Blood culture, PCR, ELISA IgM and IgG negative \\
\hline \multirow[t]{2}{*}{ Leptospira spp } & PCR positive (ct value $=30)$ & PCR positive $($ ct value $=19)$ \\
\hline & ELISA IgM, IgG negative & ELISA IgM, IgG negative \\
\hline
\end{tabular}

${ }^{a} A S T$ aspartate aminotransferase

${ }^{\mathrm{b}} A L T$ alanine aminotransferase

were missed by clinicians presumably due to nonspecific clinical presentations $[27,35,36]$. It is unclear why leptospirosis is more severe in adults than children. Contributing factors may include host susceptibility [37], Leptospira virulence [12], and changes in the immune response [38]. The observed lower frequency of leptospirosis in women is thought to be related to lower levels of outdoor activities compared with men [39], lower levels of leptospiremia [40], and clinically less severe disease [41]. However, in our study the proportion of women correctly diagnosed with leptospirosis and missed by sites was similar, suggesting the lower rates in women are not related to disease severity.

We also found evidence of co-infections with rickettsioses, as confirmed by molecular and IFA assays, and leptospirosis, as confirmed by qPCR and sero-conversion of IgM antibodies. Co-infection with these two pathogens has been reported previously and is plausible given that both share rodent vectors [42].
Reliance on MAT, the current gold-standard for serology, is impractical in certain settings due to technical requirements and expense. Since an accurate rapid diagnostic test for leptospirosis is not available, molecular tests and ELISAs for IgM can be used to inform medical management in resource-limited settings, as has also been suggested previously [43] .

Since this study was part of a larger study to identify the etiologies of acute fever requiring hospitalization, a thorough assessment of leptospirosis-associated features was not specifically conducted. This limitation means that signs typically considered indicative of Leptospira infection, such as suffusion and gastrocnemius pain, may have been under-assessed. Furthermore, co-infection with leptospirosis was not assessed in patients whose current febrile illness was already attributed to another pathogen by the Reference Laboratory. This may have resulted in an under-reporting of the true leptospirosis burden in this cohort. Another limitation is that we did 
not perform MAT, the gold standard for serological evaluation of Leptospira infection. It remains unlikely that we missed leptospirosis cases for the several reasons described above, but we lack information about the infecting serogroups, which could inform public health strategies and management of animal reservoirs. Serogroup determination would be helpful for assessment of the relationship between clinical course, epidemiology, and serogroups in Indonesia, which has not yet been well-characterized. Lastly, this study was conducted only in large Indonesian cities instead of throughout the archipelago, limiting the generalizability of our findings to the entire population.

\section{Conclusions}

Leptospirosis is an important cause of fever leading to hospitalization in Indonesia. The high proportion of leptospirosis cases missed at several sites highlights the needs for increased clinician awareness of possible clinical presentations and appropriate diagnostic approaches. There is an imminent need for the development of accurate rapid diagnostics for leptospirosis and other co-endemic pathogens. In the absence of reliable rapid diagnostic tests, leptospirosis should be included by clinicians as an important differential diagnosis of acute febrile illnesses. Dissemination of clinical information and research findings, delineation of optimal empiric management, surveillance activities to inform risk reduction, and improved access to reliable point-of-care diagnostics for leptospirosis should be prioritized by policymakers.

\section{Abbreviations \\ AFIRE: The Etiology of Acute Febrile Illness Requiring Hospitalization; DNA: Deoxyribonucleic acid; ELISA: Enzyme-linked immunosorbent assay; INA-RESPOND: Indonesia Research Partnership on Infectious Diseases; MAT: Microscopic agglutination test; MoH: Ministry of Health; qPCR: Quantitative real-time polymerase chain reaction; UTI: Urinary Tract Infection; WHO: World Health Organization}

\section{Acknowledgements \\ We would like to thank all study participants and the following study sites and teams for their participation: Dr. Cipto Mangunkusumo Hospital (Jakarta), Prof. Dr. Sulianti Saroso Infectious Disease Hospital (Jakarta), Dr. Hasan Sadikin Hospital (Bandung), Dr. Kariadi Hospital (Semarang), Dr. Sardjito Hospital (Yogyakarta), Dr. Soetomo Hospital (Surabaya), Sanglah Hospital (Denpasar), and Dr. Wahidin Soedirohusodo Hospital (Makassar). We also would like to thank Lidya Chaidir, Aly Diana, and Antonius Arditya Pradana for technical assistance with the manuscript.}

\section{Authors' contributions}

Study design: MHG, UH, BA, ET, ATA, DL, HK, KL, KTPM, MA, NL, PS, VL, CYL, AN, MK; Clinical evaluation MHG, UH, BA, ET, MMDEAHH, ATA, HK, KTPM, KL, MA, NL, PS, CYL, AN, MK; Laboratory testing: DL, GS, HK, NL, ESL, AN; Data analysis and manuscript preparation: MHG, UH, BA, ET, MMDEAHH, ESL, ATA, $\mathrm{DL}, \mathrm{GS}, \mathrm{HK}, \mathrm{KTPM}, \mathrm{KL}, \mathrm{MA}, \mathrm{NL}, \mathrm{PS}, \mathrm{VL}, \mathrm{CYL}, \mathrm{AN}, \mathrm{MK}$; All authors reviewed and approved the final manuscript.

\section{Funding}

This study was conducted by INA-RESPOND, a collaborative research partnership between NIHRD, Ministry of Health, Indonesia, and US-NIAID, NIH. This project has been funded in whole or in part with $\mathrm{MOH}$ Indonesia and Federal funds from the NIAID, NIH, under contract Nos. HHSN261200800001E and HHSN261201500003I.
The content of this publication does not necessarily reflect the views or policies of the Department of Health and Human Services, nor does mention of trade names, commercial products, or organizations imply endorsement by the U.S. Government.

\section{Availability of data and materials}

The data supporting the conclusions of this article are available upon request. Please contact dr. Herman Kosasih (email: hkosasih@ina-respond.net).

\section{Ethics approval and consent to participate}

All subjects provided written informed consent before study participation. The study was conducted in accordance with the Declaration of Helsinki, and the protocol was approved by the IRBs of Faculty of Medicine, University of Indonesia/ Dr. Cipto Mangunkusumo Hospital (451/PT02.FK/ETIK/2012), Dr. Soetomo Hospital (192/Panke.KKE/VIII/2012), and the National Institute of Health and Research and Development (NIHRD), Ministry of Health, Indonesia (KE.01.05/EC/407/2012).

\section{Consent for publication}

Not applicable.

\section{Competing interests}

The authors declare that they have no competing interests.

\section{Author details}

${ }^{1}$ Dr. Kariadi Hospital - Faculty of Medicine, Diponegoro University, Semarang, Indonesia. ${ }^{2}$ Dr. Soetomo Academic General Hospital, Faculty of Medicine Airlangga University, Surabaya, Indonesia. ${ }^{3}$ Hasan Sadikin Hospital - Faculty of Medicine, Padjadjaran University, Bandung, Indonesia. ${ }^{4}$ National Institute of Health Research and Development (NIHRD), Ministry of Health Republic of Indonesia, Jakarta, Indonesia. ${ }^{5} \mathrm{Dr}$. Sardjito Hospital - Faculty of Medicine, Public Health and Nursing, Gadjah Mada University, Yogyakarta, Indonesia. ${ }^{6}$ Tangerang District Hospital, Tangerang, Indonesia. Indonesia Research Partnership on Infectious Disease (INA-RESPOND), Badan Litbangkes, Building 4, 5th floor, Jl Percetakan Negara no 29, Jakarta 10560, Indonesia.

${ }^{8}$ Department of Internal Medicine, Udayana University, Bali, Indonesia. ${ }^{9}$ Dr. Wahidin Sudirohusodo Hospital, Makassar, Indonesia. ${ }^{10}$ Dr. Cipto Mangunkusumo Hospital, Jakarta, Indonesia. ${ }^{11}$ Prof. Dr. Sulianti Saroso Hospital, Jakarta, Indonesia. ${ }^{12}$ National Institute of Allergy and Infectious Diseases (NIAID), National Institutes of Health, Bethesda, MD, USA.

Received: 12 November 2019 Accepted: 18 February 2020 Published online: 27 February 2020

\section{References}

1. Victoriano AF, Smythe LD, Gloriani-Barzaga N, Cavinta LL, Kasai T, Limpakarnjanarat K, et al. Leptospirosis in the Asia Pacific region. BMC Infect Dis. 2009;9:147.

2. RI KK. Profil Kesehatan Indonesia 2018. Jakarta 2019.

3. Costa F, Hagan JE, Calcagno J, Kane M, Torgerson P, Martinez-Silveira MS, et al. Global morbidity and mortality of leptospirosis: a systematic review. PLoS Negl Trop Dis. 2015;9(9):e0003898.

4. Day N. Leptospirosis: epidemiology, microbiology, clinical manifestations, and diagnosis. UpToDate. 2019.

5. Musso D, La Scola B. Laboratory diagnosis of leptospirosis: a challenge. J Microbiol Immunol Infect. 2013;46(4):245-52.

6. Budihal SV, Perwez K. Leptospirosis diagnosis: competancy of various laboratory tests. J Clin Diagn Res. 2014;8(1):199-202.

7. Karyana M, Kosasih H, Samaan G, Tjitra E, Aman AT, Alisjahbana B, et al. INARESPOND: a multi-Centre clinical research network in Indonesia. Health Res Policy Syst. 2015;13:34

8. Lie KC, Aziz MH, Kosasih H, Neal A, Halim CL, Wulan WN, et al. Case report: two confirmed cases of human Seoul virus infections in Indonesia. BMC Infect Dis. 2018;18(1):578.

9. Effler PV, Bogard AK, Domen HY, Katz AR, Higa HY, Sasaki DM. Evaluation of eight rapid screening tests for acute leptospirosis in Hawaii. J Clin Microbiol. 2002;40(4):1464-9.

10. Desakorn V, Wuthiekanun V, Thanachartwet V, Sahassananda D, Chierakul W, Apiwattanaporn A, et al. Accuracy of a commercial IgM ELISA for the diagnosis of human leptospirosis in Thailand. Am J Trop Med Hyg. 2012; 86(3):524-7. 
11. Stoddard RA, Gee JE, Wilkins PP, McCaustland K, Hoffmaster AR. Detection of pathogenic Leptospira spp. through TaqMan polymerase chain reaction targeting the LipL32 gene. Diagn Microbiol Infect Dis. 2009;64(3):247-55.

12. Thaipadungpanit J, Wuthiekanun V, Chierakul W, Smythe LD, Petkanchanapong W, Limpaiboon R, et al. A dominant clone of Leptospira interrogans associated with an outbreak of human leptospirosis in Thailand. PLoS Negl Trop Dis. 2007;1(1):e56.

13. CDC. Leptospirosis (Leptospira interrogans) 2013 Case Definition 2013. https://wwwn.cdc.gov/nndss/conditions/leptospirosis/case-definition/2013/.

14. Laras K, Cao BV, Bounlu K, Nguyen TK, Olson JG, Thongchanh S, et al. The importance of leptospirosis in Southeast Asia. Am J Trop Med Hyg. 2002; 67(3):278-86.

15. Gasem MH, Farida H, Ahmed A, Severin JA, Suryanto A, Isbandrio B, et al. Are pathogenic Leptospira species agents of community-acquired pneumonia? Case reports of leptospirosis presenting as pneumonia. J Clin Microbiol. 2016:54(1):197-9.

16. Gasem MH, Wagenaar JF, Goris MG, Adi MS, Isbandrio BB, Hartskeerl RA, et al. Murine typhus and leptospirosis as causes of acute undifferentiated fever, Indonesia. Emerg Infect Dis. 2009;15(6):975-7.

17. Groen J, Koraka P, Osterhaus A, Suharti C, van Gorp E, Sutaryo J, et al. Serological evidence of human hantavirus infections in Indonesia. Infect. 2002;30(5):326-7.

18. Lokida D, Budiman A, Pawitro UE, Gasem MH, Karyana M, Kosasih H, et al. Case report: Weil's disease with multiple organ failure in a child living in dengue endemic area. BMC Res Notes. 2016;9(1):407.

19. Wennike N, Bacon M. The dangers of volunteer work in rural Asia--acute lung injury as the first manifestation of Weil's disease. Eur J Intern Med. 2008;19(8):e92-3.

20. Goarant C, Colot J, Faelchlin E, Ponchet M, Soupe-Gilbert ME, Descloux E, et al. An exotic case of leptospirosis imported into an endemic area. Travel Med Infect Dis. 2014;12(2):198-200.

21. Jaureguiberry S, Roussel M, Brinchault-Rabin G, Gacouin A, Le Meur A, Arvieux C, et al. Clinical presentation of leptospirosis: a retrospective study of 34 patients admitted to a single institution in metropolitan France. Clin Microbiol Infect. 2005;11(5):391-4.

22. Covic A, Goldsmith DJ, Gusbeth-Tatomir P, Seica A, Covic M. A retrospective 5-year study in Moldova of acute renal failure due to leptospirosis: 58 cases and a review of the literature. Nephrol Dial Transplant. 2003;18(6):1128-34.

23. Tique V, Mattar S, Miranda J, Oviedo M, Noda A, Montes E, et al. Clinical and epidemiological status of leptospirosis in a tropical Caribbean area of Colombia. Biomed Res Int. 2018;2018:6473851.

24. CDC. Leptospirosis Fact Sheet for Clinicians. 2018. https://www.cdc.gov/ leptospirosis/pdf/fs-leptospirosis-clinicians-eng-508.pdf. Accessed 3 Jan 2020.

25. Panaphut T, Domrongkitchaiporn S, Vibhagool A, Thinkamrop B, Susaengrat W. Ceftriaxone compared with sodium penicillin $\mathrm{g}$ for treatment of severe leptospirosis. Clin Infect Dis. 2003;36(12):1507-13.

26. Raptis L, Pappas G, Akritidis N. Use of ceftriaxone in patients with severe leptospirosis. Int J Antimicrob Agents. 2006;28(3):259-61.

27. Libraty DH, Myint KS, Murray CK, Gibbons RV, Mammen MP, Endy TP, et al. A comparative study of leptospirosis and dengue in Thai children. PLoS Negl Trop Dis. 2007;1(3):e111.

28. Visweswaran R, Sreelatha M. Leptospirosis: a case of "overdiagnosis" and "underdiagnosis". J Acad Med Sci. 2012;2(1):38-9.

29. Syhavong B, Rasachack B, Smythe L, Rolain JM, Roque-Afonso AM, Jenjaroen $K$, et al. The infective causes of hepatitis and jaundice amongst hospitalised patients in Vientiane, Laos. Trans R Soc Trop Med Hyg. 2010;104(7):475-83.

30. Burdmann EA, Jha V. Acute kidney injury due to tropical infectious diseases and animal venoms: a tale of 2 continents. Kidney Int. 2017;91(5):1033-46.

31. Waggoner JJ, Balassiano I, Abeynayake J, Sahoo MK, Mohamed-Hadley A, Liu Y, et al. Sensitive real-time PCR detection of pathogenic Leptospira spp. and a comparison of nucleic acid amplification methods for the diagnosis of leptospirosis. PLoS One. 2014;9(11):e112356.

32. Niloofa R, Fernando N, de Silva NL, Karunanayake L, Wickramasinghe $H$, Dikmadugoda N, et al. Diagnosis of leptospirosis: comparison between microscopic agglutination test, IgM-ELISA and IgM rapid Immunochromatography test. PLoS One. 2015;10(6):e0129236

33. Reller ME, Bodinayake C, Nagahawatte A, Devasiri V, Kodikara-Arachichi W, Strouse JJ, et al. Leptospirosis as frequent cause of acute febrile illness in southern Sri Lanka. Emerg Infect Dis. 2011;17(9):1678-84.

34. Levett PN. Leptospirosis. Clin Microbiol Rev. 2001;14(2):296-326.
35. Agesilas F, Gey F, Monbrunt A, Combes JC, Llanas B, Schlossmacher P, et al. Acute leptospirosis in children in Reunion Island: a retrospective review of 16 cases. Arch Pediatr. 2005;12(9):1344-8.

36. Marotto PC, Marotto MS, Santos DL, Souza TN, Seguro AC. Outcome of leptospirosis in children. Am J Trop Med Hyg. 1997;56(3):307-10.

37. Lingappa J, Kuffner T, Tappero J, Whitworth W, Mize A, Kaiser R, et al. HLADQ6 and ingestion of contaminated water: possible gene-environment interaction in an outbreak of leptospirosis. Genes Immun. 2004;5(3):197-202.

38. Fialho RN, Martins L, Pinheiro JP, Bettencourt BF, Couto AR, Santos MR, et al. Role of human leukocyte antigen, killer-cell immunoglobulin-like receptors, and cytokine gene polymorphisms in leptospirosis. Hum Immunol. 2009; 70(11):915-20.

39. Sakundarno M, Bertolatti D, Maycock B, Spickett J, Dhaliwal S. Risk factors for leptospirosis infection in humans and implications for public health intervention in Indonesia and the Asia-Pacific region. Asia Pac J Public Health. 2014;26(1):15-32.

40. Agampodi SB, Matthias MA, Moreno AC, Vinetz JM. Utility of quantitative polymerase chain reaction in leptospirosis diagnosis: association of level of leptospiremia and clinical manifestations in Sri Lanka. Clin Infect Dis. 2012; 54(9):1249-55.

41. Jansen A, Stark K, Schneider T, Schoneberg I. Sex differences in clinical leptospirosis in Germany: 1997-2005. Clin Infect Dis. 2007;44(9):e69-72.

42. Parker TM, Murray CK, Richards AL, Samir A, Ismail T, Fadeel MA, et al. Concurrent infections in acute febrile illness patients in Egypt. Am J Trop Med Hyg. 2007;77(2):390-2

43. Goris MGA, Leeflang MMG, Boer KR, Goeijenbier M, van Gorp ECM, Wagenaar JFP, Hartskeerl RA. Establishment of Valid Laboratory Case Definition for Human Leptospirosis. J Bacteriol Parasitol. 2011;3(2).

\section{Publisher's Note}

Springer Nature remains neutral with regard to jurisdictional claims in published maps and institutional affiliations.

Ready to submit your research? Choose BMC and benefit from:

- fast, convenient online submission

- thorough peer review by experienced researchers in your field

- rapid publication on acceptance

- support for research data, including large and complex data types

- gold Open Access which fosters wider collaboration and increased citations

- maximum visibility for your research: over $100 \mathrm{M}$ website views per year

At $\mathrm{BMC}$, research is always in progress.

Learn more biomedcentral.com/submissions 